\title{
Threats to Established Companies from Increasing Digitalization
}

\author{
Marco Pister \\ University of Economics in Bratislava, Department of Management
}

\begin{abstract}
In today's world, companies have to deal more than ever with increasing globalization/internationalization and enormous competitive pressure. Strong competitive pressure leads to faster and faster innovation cycles, constant technical innovations and programmes for further cost reductions. In recent years, digitalization has added another challenge for established companies. New competitors are blurring industry models through digitalization and offerings based on disruptive innovation, proven business models are no longer suitable from one day to the next and established companies are competing with service or usage offerings. Such service or usage offerings will almost always be considered by the millennial or alwayson generation and pose significant risks to established companies.
\end{abstract}

Keywords: disruptive innovation, digitalization, risks to established companies

\section{Introduction}

Companies have been facing significant challenges for several years. In the literature, the causes for this are seen in particular as internationalization or globalization, increasingly differentiated customer wishes, saturated markets and a lack of opportunities for differentiation (Institut der Deutschen Wirtschaft Köln, 2016, p. 1520 ). Digitalization is still a comparatively new challenge for established companies, as it leads to the emergence of new competitors with new services or value propositions, blurs existing industry boundaries and can affect the economic success of existing companies in these industries (Eckert, 2014, p. 263).

This paper addresses the question of what threats digitalization poses to established companies. To systematize the threats, this thesis uses two conceptual approaches: the blue oceans strategy by Kim and Mauborgne (2005) and the disruptive innovation considerations by Christensen (1997). 


\subsection{Approach}

To answer the research question, this thesis is divided into four chapters. The second chapter deals with the theoretical foundations of the blue oceans approach and the concept of disruptive innovation. The chapter concludes with an identification of similarities and differences between the two approaches. The third chapter examines different forms of innovation in the context of digitalization. In each case, the innovations are presented using empirically comprehensible examples. The document is concluded with the fourth chapter, Conclusion \& Outlook.

\section{Theoretical background to disruption and digitalization}

\subsection{The concept of the blue ocean}

The concept of the blue ocean goes back to Kim and Mauborgne (2005). The authors refer to different types of markets as red and blue oceans. Red oceans represent the currently known industries with clear industry boundaries and rules of competition accepted by all actors. In these markets, competitors try to outperform each other in order to secure the largest possible market share with respect to existing demand. The need to outperform each other leads to strong competition between the operating companies. Furthermore, as differentiation from the competition becomes increasingly difficult, this situation has a negative impact on the profitability of the companies involved: If companies' services are not distinguishable for the customer, competition is based on price, which poses the risk of ruinous price wars (Kim \& Mauborgne, 2005, pp. 16-17).

Blue oceans, on the other hand, according to Kim and Mauborgne (2005), stand for currently unknown markets. Companies in a blue ocean do not use the competition as a point of reference; rather, the goal is to avoid the competition by creating a benefit for customers. The rules of the game do not yet exist in the markets created in this way; these are only defined by a company, the innovator in this market. This can happen, for example, by means of the definition of standards. Ultimately, an actor in a blue ocean does not try to find solutions to existing customer problems, rather their quest is to redefine the problem. The essential advantage of a blue ocean is thus to be seen in the fact that the direct connection between benefits and costs is cancelled out. In this respect, a market leader cannot only clearly distinguish themselves from the competition by creating a benefit innovation, but at the same time they can also offer this service at lower costs, which has a positive effect on the profitability of the company (Kim \& Mauborgne, 2005, pp. 15-17).

In order to open up new markets or penetrate blue oceans, Kim and Mauborgne (2005, pp. 26-27) are guided by four key questions:

Which elements of the former business model or offering that were previously taken for granted in the industry can be eliminated? 
Which elements can be lowered to far below the standard previously taken for granted in the sector?

Which elements that have not yet been offered in the sector can or should be newly created?

Which elements can be raised far above the industry standard?

By adapting their current business model on the basis of these four guiding questions, companies change their strategic contour and can thus, in the best case, achieve the above-mentioned differentiation from the competition with lower costs of their own (Kim \& Mauborgne, 2005, pp. 27-30).

\subsection{Disruptive innovation according to Christensen}

Christensen's (1997) central contribution to innovation research can be seen in the fact that he introduced or developed a new systematization: Up to now, innovations have been differentiated into instrumental or radical innovations exclusively on the basis of the type of innovation object (for example, process innovation, product innovation) and on the basis of the innovation history. Christensen supplements the categorization with the dimension "evolutionary" or "disruptive", which refers to product performance (Christensen, 1997, pp. 10-12). Christensen (1997) describes innovations as evolutionary if they are based on something that already exists:

I call these sustaining technologies. Some sustaining technologies can be discontinuous or radical in character, while others are of an incremental nature. What all sustaining technologies have in common is that they improve the performance of established products, along the dimensions of performance that mainstream customers in major markets have historically valued. (S. 11)

Disruptive innovations, on the other hand, according to Christensen (1997), are characterized by a value proposition that is clearly different from the previous offering. Products based on disruptive innovations are worse in terms of performance than the current market offering when they are launched, but the advantages associated with the changed value proposition open up the possibility for the provider to open up new markets. Christensen (1997, p. 11) identifies five central principles or characteristics in connection with disruptive innovations.

The first principle manifests itself in a company's dependence on resources from customers and investors: Christensen assumes that resources are used in a company to increase customer satisfaction and improve profitability, since a company can only survive in the long term in this way. Successful companies, Christensen continues, go through processes that allow them to discard those investments that do not contribute to increasing customer satisfaction or profitability. However, it is precisely these processes that would hinder disruptive innovations, since, as explained above, these are initially associated with lower customer value and/or lower profitability. In 
this respect, established companies can maintain their market leadership with evolutionary innovations from wave to wave (see Figure 1), but recognize disruptive innovations too late and thus fall behind the innovator(s) in the market (Christensen, 1997, p. 14).

The second principle relates to market size. Christensen (1997, pp. 14-15) assumes that disruptive innovations are regularly accompanied by the emergence of small markets. For established companies, however, these markets are often too small to satisfy investors' expectations in financial terms by serving them. In this respect, disruptive innovations are usually attractive for smaller companies or a single organizational unit, but not for larger companies.

Christensen (1997, pp. 15-16) describes the failure of market research with regard to identifying disruptive innovations in the third principle. He assumes that a market for disruptive innovations does not yet exist. Since companies in the context of market research only try to identify the current needs of customers and respond to them in an appropriate way, they will not recognize disruptive innovations. This would mean, for example, that the customer knows his needs that will arise in the future.

\section{Figure 1 - Difference between evolutionary and disruptive innovation}

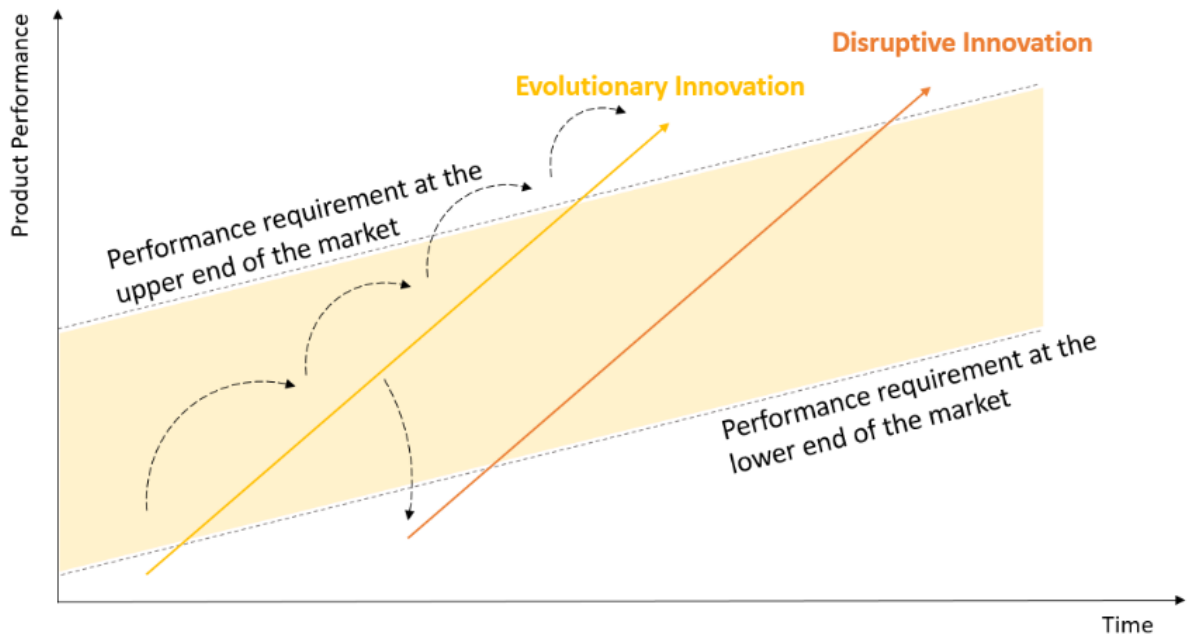

Source: Knöchelmann, 2014, n.d.

The fourth principle describes that companies have ingrained patterns both at the process level and with regard to the corporate culture or corporate values. These patterns relate not only to the distribution of resources but also to the way of working, which may not necessarily prove conducive to disruptive innovation.

In his fifth and final principle, Christensen addresses the relationship between supply and demand in terms of performance (see Figure 1). As can be seen, evolutionary 
innovations exceed the performance requirements of the market at a certain point. The reason for this development can be seen in the fact that existing technologies develop faster than the needs of customers. From a certain point onwards, an overdevelopment can be observed. In contrast, destructive innovations start at the lower end of the performance requirements, are therefore initially not perceived as competition by established companies, but after a certain point on the time axis they precisely meet customer needs - and do so at a lower price than established companies (Christensen, 1997, pp. 15-17).

\subsection{Blue oceans and disruptive innovation}

Common to both concepts is the idea of opening up new markets in order to escape competition in existing markets. The blue oceans approach sees four possibilities for this: eliminating, creating, lowering and raising elements of the existing offer or business model. The starting point here is therefore something that already exists, in Christensen's understanding an evolutionary innovation. Disruptive innovation, on the other hand, creates a completely new offer detached from the existing one. However, there is an overlap with the blue oceans approach insofar as newness in Christensen's understanding can certainly be understood with the creation of new elements in the context of the blue oceans concept.

\section{Dangers for established providers through disruption in the context of digitalization}

\subsection{Dissolving industry boundaries}

A first danger for established companies or suppliers can be seen in the fact that developments in the area of digitalization and especially in the context of Industry 4.0 are blurring or dissolving industry boundaries and competitors from outside the industry are entering the established market of established manufacturers (Eckert, 2014 , p. 263). This is clearly illustrated by the example of the automotive industry, where two different types of competitors pose competition for established companies through disruptive innovations.

The first competitor is the so-called mobility service provider, who completely turns the prevailing logic of the automotive industry upside down (see Figure 1) (BVDW, 2015, p. 1-2). Until now, ownership models have dominated in the vehicle sector, i.e. a customer acquires ownership or at least possession of a vehicle. Alternatively, there is the possibility of renting a vehicle for individual cases via corresponding service providers (in this case car rental - second). The latter, however, is generally associated with greater expense, as the vehicle can only be picked up at certain locations and must also be returned there.

Mobility service providers have a completely new perspective on the subject of vehicles, offering customers the opportunity to rent vehicles exactly when they are needed with little bureaucratic effort and a high level of convenience. In this way, 
mobility service providers generate benefits for the customer in several respects: $0 n$ the one hand, the customer always has access to a vehicle when it is needed, without any administrative effort (for example, booking and billing via mobile device). Secondly, such a service offer no longer necessarily requires the customer to own a vehicle, which represents a considerable liquidity advantage for the customer. Finally, this business model also addresses current social trends, such as the desire for a high degree of flexibility or the fact that vehicles no longer have such a strong impact as a status symbol (Wallentowitz, Freialdenhoven \& Olschewski, 2009, p. 15; Winterhoff et al., 2009, p. 3-23).

\subsection{Loss of value added potential through platforms}

Another danger for established providers that can arise from disruptive innovations is the loss of value added potential through platforms. This danger exists in particular in connection with so-called multi-sided platforms. This type of platform is characterized by the fact that it brings together several different customer groups. These customer groups are interdependent and the platform thus performs an intermediary task. Digitalization has had a significant influence on the development of platforms, as developments in the field of information and communication technology (ICT) have made it much easier to bring together different people or organizations, and additional services can also be offered (Osterwalder \& Pigneur, 2011, p. 82).

Platforms from the field of logistics can be seen as an example of the development over time: As early as the 1970 s, there were platforms on which supply and demand for freight space were brought together. However, their use was associated with considerable risks (for example, the posting of bogus offers or uncertainty about the quality of the service provided, especially in connection with special freight). With the advent of ICT, the use of platforms not only became easier, the risk for the user could also be significantly reduced through the integration of additional services (for example, rating of users, credit checks) (Grotemeier \& Lehmacher, 2016, pp. 75-76).

Platforms regularly pose a risk for established providers when competitors from outside the sector, especially from the ICT sector, set up such platforms and thus extract value creation from established providers. This is also particularly relevant in the context of digitalization, as platforms can be used to sell not only hardware but also digital content or services, as shown in the example of the logistics platform, which can significantly exceed the value added of the original core service (Osterwalder \& Pigneur, 2011, pp. 82-105).

Another business model based on the platform idea in the area of mobility includes so-called ride-sharing services (second competitor). Here, passengers are referred to private drivers via the internet or a smartphone app, for whom there is an earning opportunity. An example of this is Uber. For this, a user has to install the corresponding application on the mobile device, which can then be used worldwide. 
Only the credit card data must be deposited for use. The fare can be calculated in advance via the application. The actual fare to be paid takes into account the route as well as current traffic or congestion. After completing the journey, the driver can be rated. Payment is made by credit card, with the company retaining $20 \%$ of the fare as commission (Haucap et al., 2015, pp. 18-19).

\section{Figure 2 - Comparison of ride-sharing service vs. taxi company}

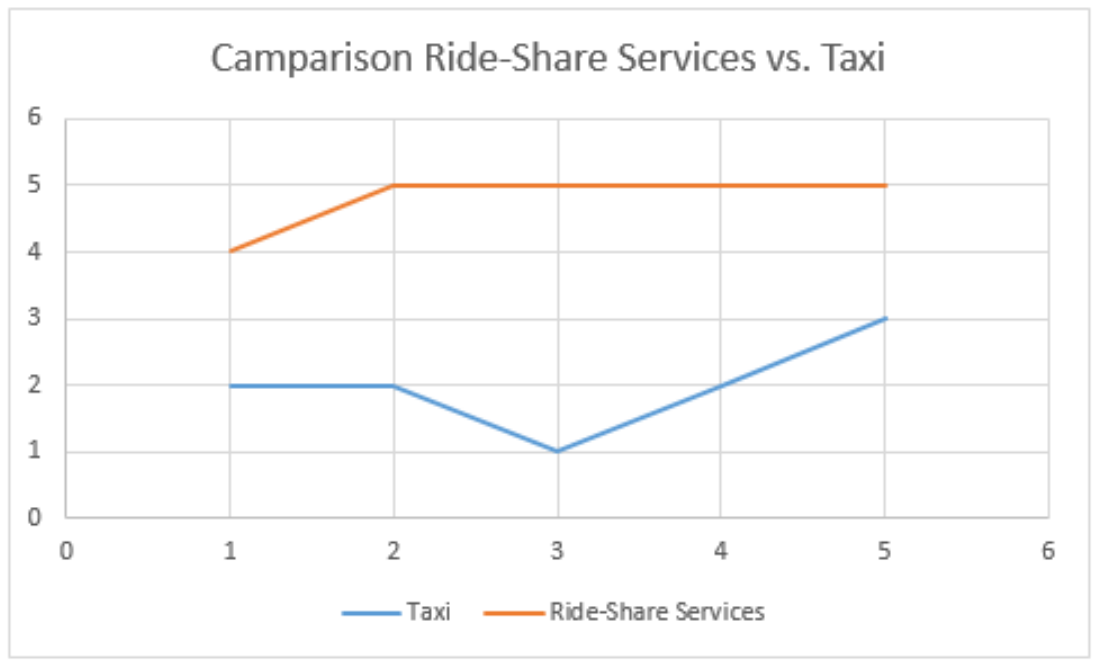

Source: Own illustration

With regard to the characteristic "disruptive", the fifth of Christensen's principles applies to the platforms listed, namely that the service provided by such a platform is initially small for the customer and the danger is thus not recognized by established manufacturers. This is due to the fact that the value of the platform for one user group depends largely on the number of users on the other side (Osterwalder \& Pigneur, 2011, p. 82). Example: The value of the sales platform eBay is higher for a potential buyer the more sellers he finds on this platform. Conversely, the more buyers regularly visit the platform, the more attractive it is for a seller. In this respect, newly established platforms have a relatively low value for the user groups at the beginning, but when a certain threshold of the different customer groups is exceeded, a higher benefit can arise than with traditional offerings.

If an established manufacturer recognizes the emergence of a platform too late, they may no longer be able to react because, for example, appropriate standards have been set, exclusivity has been achieved or second, third or fourth platforms do not generate any additional value for customers and are therefore not accepted by them. 


\subsection{Failure of disruptive innovations}

Another example that can be used to illustrate some of the above principles of disruptive innovation is the development of smartphones. Until 2005, the mobile phone industry was in the phase of evolutionary innovations, where mobile phones, for example, became more powerful, had larger displays with more colours, could store more phone numbers or became smaller and better to use (Erle, 2016, n.d.). Nokia brought a disruptive innovation to the market with the N95 in 2006. This mobile phone eventually had all the features that characterize today's smartphones: Digital camera, memory, media player, navigation system etc. (Bielinis, 2011, n.d.).

So up to this point, it can be said that Nokia, as an established company and market leader in the mobile phone sector, managed to bring a disruptive innovation to the market and thus mastered principles number 3 and 4 (failure of market research and entrenched patterns at the process and value level) listed above with flying colours. Nevertheless, Nokia disappeared from the market as a brand a few years later. The reason for this can be seen in the fact that Nokia "steamrollered" consumers with the N95 and the market was ultimately not yet ready for this disruptive innovation. On the other hand, both the N95 and the subsequent devices had considerable deficits in terms of usability for the user. This was not only evident in the operation of the device, but also in the use of its own platform for mobile applications. Ultimately, this meant that the sum of the product's performance was too low despite its innovative features (Bielinis, 2011, n.d.).

Competitors such as Apple took some time to bring comparable devices to the market, but in addition to improved technical specifications, these featured above all better usability - which was a major selling point in view of users who were still inexperienced with smartphones. After both Apple and Google were able to achieve success with their developed platforms, Nokia was no longer able to catch up (Bielinis, 2011, n.d.).

Ultimately, from the point of view of disruptive innovation according to Christensen, it remains to be said that Nokia created it, but then was not able to carry out the necessary evolutionary innovations in order to gradually achieve improved customer benefits. This is where other companies had advantages, for example Apple due to its experience in the PC and desktop sector. In this way, Nokia was not able to use its lead in time as an innovator to be able to take a market-leading position in the long term. Ultimately, it could be said that Nokia introduced the innovation that sealed the company's downfall. 


\section{Figure 3 - Mobile Phones in comparison}

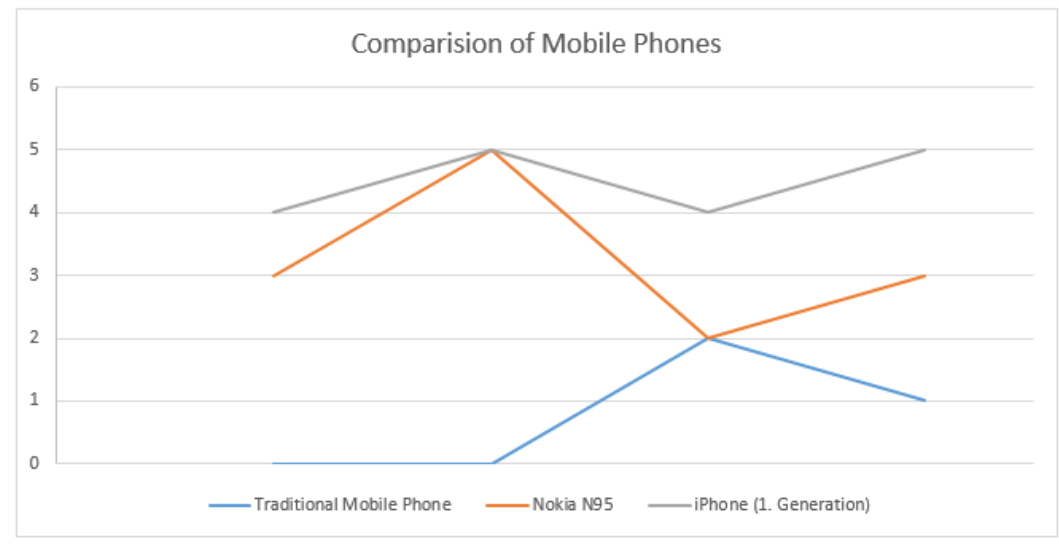

Source: Own illustration

In addition, there is the fifth principle in Christensen's logic: Nokia believed that the smartphone market was only a sub-segment of the mobile phone market. It was assumed that within a very short time every mobile device would be a smartphone (Bielinis, 2011, n.d.).

\subsection{Loss of the customer interface}

Another danger for established manufacturers can be seen in the fact that the interface to the customer can be lost through disruptive innovations. The smartphone market can also be used as an example for this: Because there are only a few operating systems for mobile devices, manufacturers have to choose a platform - but this means they lose control over the customer interface. The loss of the interface is particularly relevant because, on the one hand, data is generated via this interface (for example, about usage behaviour), which can be used to offer new services for the customer, and on the other hand, additional digital content can also be sold via the interface (Haug, 2013, pp. 36-42).

Another example is the customer interface in a vehicle: Here, too, there is a fundamental danger that third-party providers from other sectors (here: the ICT sector) can locate themselves in the vehicle with their offers, generate data and either develop their own services on the basis of this data or sell the data.

If, for example, a car manufacturer is not in a position to offer their own navigation software, they must fall back on a third-party provider who, however, may occupy the interface to the customer. This is particularly relevant with regard to the development of a self-driving vehicle. In order not to lose the customer interface in this context, the manufacturers Audi, BMW and Daimler have acquired the last remaining licence of a navigation software (here: the map service "Here" from the 
telecommunications company Nokia), thereby preventing companies such as Google and similar companies from penetrating their vehicles (Zeit Online, 2015, n.d.).

\section{Conclusion and Outlook}

This work has highlighted a number of situations in which established companies face risks resulting from disruptive innovations. This is particularly the case when disruptive innovations blur industry boundaries and new providers enter the traditional markets of established suppliers. Likewise, new business models, e.g. based on the platform idea, can lead to companies losing value added potential or even the interface to the customer - this is a significant risk in the context of datadriven business models.

One possible response to the emerging risks is for established companies to tackle disruptive innovations themselves. The example of Nokia has shown that this can succeed, although the company was unable to profit from it in the long term because the innovation was not pursued with the necessary consistency. Under certain circumstances, it can make sense if either the search for disruptive innovations is already carried out in outsourced units of the company or if a spin-off is carried out at the latest when a decision is made in favour of a disruptive innovation, so that independent development can take place and the innovation process is not hindered by "thinking along old lines".

Another way of minimizing risk for large companies is to leave the development and market testing to other companies, such as start-ups, and to acquire these companies if they are successful.

\section{References}

[1] Bielinis, S. (2011). How Nokia was disrupted. Abgerufen am 04.10.2016 von http://www.unwiredview.com/2011/06/22/how-nokia-was-disruptedpart-1/

[2] BVDW. (2015). Diskussionspapier: Geschäftsmodelle. Abgerufen am 04.10 .2016 von http://www.bvdw.org/mybvdw/media/download/diskussionspapier-iotconnected-cars-geschaeftsmodelle.pdf?file $=3904$

[3] Christensen, C. M. (1997). The Innovator's Dilemma. When New Technologies Cause Great Firms to Fail. Boston, Massachusetts: Harvard Business School Press. ASIN B009XR5W1S.

[4] D'Aveni, R. A. \& Gunther R. (2007). Hypercompetition. Managing the Dynamics of Strategic Maneuvering. In: C. Boersch \& R. Eischen (Hrsg.), Das Summa Summarum des Management (S. 83-94). Wiesbaden: Gabler. ISBN 978-3834905192. 
[5] Eckert, R. (2014). Business Model Prototyping. Wiesbaden: Gabler. ISBN 978365806107.

[6] Erle, C. (2016). Erfolgreich sterben. Disruption \& Innovation Culture am Beispiel von Nokia. Abgerufen am 04.10.2016 von http://www.managementcircle.de/blog/erfolgreich-sterben-disruption-innovation-culture-ambeispiel-von-nokia-teil-1/

[7] Grotemeier, C. \& Lehmacher, W. (2016). Die Plattform-Ökonomie: Chancen und Herausforderungen für den Wirtschaftsbereich Logistik. In C. Kille \& M. Meißner (Hrsg.), Logistik trifft Digitalisierung. Auswirkungen auf die Entwicklung In 2016. Ergebnisse Des Herbstgipfels 2015 (S. 74-81). Hamburg: DVV Media Group GmbH.

[8] Haucap, J., Pavel, F., Aigner, R., Arnold, M., Hottenrott, M. \& Kehder, C. (2015). Chancen der Digitalisierung auf Märkten für urbane Mobilität: Das Beispiel Uber. Abgerufen am 04.10.2016 von http://dupress.de/fileadmin/redaktion/DUP/Info_PDFs/DICE_OP/073_OP_ Haucap_Pavel_Aigner_Arnold_Hottenrott_Kehder.pdf

[9] Haug, K. (2013). Digitale Potenziale für den stationären Handel durch Empfehlungsprozesse, lokale Relevanz und mobile Geräte (SoLoMo). In G. Heinemann (Hrsg.), Digitalisierung des Handels mit ePace (S. 27-50). Wiesbaden: Springer. ISBN 978-3658012991.

[10] Institut der Deutschen Wirtschaft Köln. (2016). Die gesellschaftliche Verantwortung von Unternehmen angesichts neuer Herausforderungen und Megatrends. Abgerufen am 04.10.2016 von https://www.bertelsmannstiftung.de/fileadmin/files/BSt/Publikationen/GrauePublikationen/Studie_ BS_Die-gesellschaftliche-Verantwortung-von-Unternehmen-angesichtsneuer-Herausforderungen-und-Megatrends_2016.pdf

[11] Kim, C. W. \& Mauborgne, R. (2005). Der Blaue Ozean als Strategie. München: Hanser. ISBN 978-3446402171.

[12] Knöchelmann, M. (2014). Disruptive Innovation: Clayton Christensens Ansatz. Abgerufen am $04.10 .2016 \quad$ von http://www.lepublikateur.de/2014/04/03/disruptive-innovation-claytonchristensens-ansatz/

[13] Naisbitt, J. (2007). Mindset! Wie wir die Zukunft entschlüsseln. München: Carl Hanser. ISBN 978-3446410008.

[14] Osterwalder, A. \& Pigneuer, Y. (2011). Business Model Generation. Ein Handbuch für Visionäre, Spielveränderer und Herausforderer. Frankfurt, New York: Campus. ISBN 978-3593394749 
[15] Wallentowitz, H., Freialdenhoven, A. \& Olschewski, I. (2009). Strategien in der Automobilindustrie: Technologietrends und Marktentwicklungen. Wiesbaden: Vieweg+Teubner. ISBN 978-3834807250.

[16] Winterhoff, M., Kahner, C., Ulrich, C. \& Sayler, P. W. (2009). Zukunft der Mobilität 2020. Abgerufen am 04.10.2016 von http://www.adlittle.de/uploads/tx_extthoughtleadership/ADL_Zukunft_der _Mobilitaet_2020_Langfassung.pdf

[17] Zeit Online. (2015). BMW, Daimler und Audi kaufen Kartendienst Here. Abgerufen am 04.10.2016 von http://www.zeit.de/digital/2015-08/bmwaudi-daimler-kauf-here-nokia 